\title{
From the Guest Editor for the December 2014 Issue of Sexuality and Disability: The Emerging Intersection of Sexuality and Disability in the Profession of Social Work
}

\author{
Joseph A. LoGiudice
}

Published online: 6 November 2014

(C) Springer Science+Business Media New York 2014

Welcome to this special theme issue on The Intersection of Sexuality and Disability: Implications for the Social Work Profession! I am proud, excited, and grateful to introduce scholars, practitioners, and intellectuals to emerging ideas, conceptions, research, and directions centered on a typically marginalized and overlooked topic in social worksexuality and disability. Let me begin by providing the context to which this special theme issue originated, what you will encounter in intellectual and practical knowledge from the articles herein, and the potential roadmap of this area of inquiry.

I am a councilor on the Council on Disability and Persons with Disabilities (CDPD) of the Council on Social Work Education (CSWE). I have been part of CDPD for the past 2 years and during that time have recommended topics to address in presentations, trainings, and curriculum within the social work profession. One such topic that I felt strongly about is how social workers are taught and trained in the area of intersectionality research, with a focus on Lesbian, Gay, Bisexual, Transgender, Queer/Questioning (LGBTQ) individuals with disabilities. Intersectionality is a concept that I encountered as part of doctoral research, but never once heard in graduate classes in social work, nor in the field. As social workers, who attend schools accredited by the CSWE, it is mandatory that we attend the traditional diversity survey course in which learning is focused on identities, but they are conceptualized and understood as separate rather than as intersecting. This situation creates a place where and how social workers begin to make sense of the lived experiences of people's identity categories, while accounting for power, privilege, and oppression at the institutional level. The CSWE [1] has emphasized in its Educational Policy and Accreditation Standards (EPAS) that accredited schools are required to teach students about the dimensions, variability, and intersectionality of identities and the application of social justice. However, when one looks for research in this area, a gap

\footnotetext{
J. A. LoGiudice $(\bowtie)$

Ph.D. Program in Social Work, School of Social Work, Adelphi University, One South Avenue Box 701, Garden City, NY 11530-0701, USA

e-mail: josephlogiudice2@mail.adelphi.edu
} 
exists in the production of social work knowledge fully realizing the implications of intersectionality $[4,6]$.

Thus, the first step in this process was the creation of a presentation, entitled Disability and Sexuality: What Social Worker Educators Should Know [5], which was given by four councilors of the CDPD, in October 2013, at the CSWE's Annual Program Meeting. The presentation was well-received by emerging scholars in the social work profession, and attendees were eager to know more on what social work could do to enhance our knowledge in this area. The second step occurred when I suggested to CDPD a proposal for a special theme issue that was based on the aforementioned presentation, but with the added aspect of framing it through an intersectionality perspective. Councilors agreed overwhelmingly that our profession's commitment to a population generally oppressed should receive greater attention in the professional journals, so that this particular discourse becomes a part of the master narratives in social work. When I presented a proposal to Editor-in-Chief, Dr. Sigmund Hough, he welcomed it, and with such appreciation and enthusiasm, the journey began with the collection of submissions.

The authors' articles generate scholarship on a range of vital, significant, and illuminating issues that arise in social work as it relates to sexuality and disability. In Tales of a Reluctant Sex Radical: Barriers to Teaching the Importance of Pleasure for Wellbeing, Sloane reveals the popular and professional discourses about cultural expectations of sexual pleasure for individuals with disabilities, where access is denied to discussions and education on sexual pleasure. She indicates social work educators should teach students about sexual pleasure by hinging on its dimensionality, engaging it from the client's perspective, and boosting dialogue.

According to Tennille, Solomon, and Bohrman, they advocate for the implementation in social work curriculum of an adapted version of the Field Instructors Extending EvidenceBased Practice Learning in Dyads (FIELD) Model for the field instructor and social work student dyad. The FIELD Model can teach techniques in motivational interviewing for the purpose of addressing practice competencies of sexuality and intimacy for persons living with psychiatric disabilities. The research, as reported in their article, Using the FIELD Model to Prepare Social Work Students and Field Instructors on Sexuality and Intimacy for Persons with Psychiatric Disabilities, underscores the lack of inclusion in the domain of sexuality and intimacy for persons with psychiatric disabilities.

In Discourse Analysis of Sexuality Education Curriculum: FLASH for Special Education, Winges-Yanez cogently reports that the dominant discourse(s) and discursive frameworks in the Family Life And Sexual Health (FLASH) sexuality education curriculum for special education taught in King Country, Washington, and Multnomah County, Oregon, that maintains the concept of intellectual/developmental disability (I/DD) without respect for sexuality. Further, Winges-Yanez avers social workers should be conduits for ensuring sexuality is part of the discourse(s) for I/DD sexuality education since is an ethical concern for social workers as outlined in the National Association of Social Workers' [7] Code of Ethics.

In a phenomenological study, entitled Sexual Experiences of Adults with Physical Disabilities: Negotiating with Sexual Partners, Kattari captures the experiences of nine adults with physical disabilities and their negotiations around sexual activities with current, former, and potential sexual partners. Kattari states that research which explores individuals with physical disabilities and their sexual negotiations can be a tool to teach social workers how to support clients with physical disabilities in the area of sexuality and relationship - a conversation noticeable avoided by most professionals who engage with individuals with disabilities. 
In an exploratory study, entitled Remember Our Voices Are Our Tools: Sexual SelfAdvocacy as Defined by People with Intellectual and Developmental Disabilities, Friedman, Arnold, Owen, and Sandman enlisted self-advocates with intellectual and developmental disabilities (IDD) on their definitions and experiences around sexual self-advocacy. Based on the discussions with thirty-five self-advocates on sexual self-advocacy, the following seven themes emerged: knowing and respecting myself, respect for others, my choices, speaking up, respect my rights, getting information, and healthy relationships. Their research is instrumental in enlarging the understanding and conceptualization of sexual self-advocacy for individuals with IDD, and thus emphasizes the value and importance of the IDD population's experiences on sexuality for further research, policy, practice, and services.

Finally, Intersecting and Embodied Identities: A Queer Woman's Experience of Disability and Sexuality, Drummond and Brotman report on the narrative of a gender nonconforming, young, queer women with a disability who has encountered heterosexism, homophobia, and ableism at the personal and institutional levels. In exploring the personal lived experiences of individuals who possess multiple marginalized identities, the authors indicate this can be the impetus for enhancing social service delivery with respect for the intersectionality of identity.

In the academic arena, the concept of intersectionality has existed for nearly 25 years, beginning with the pioneering work of Black, critical race, feminist legal scholar, Crenshaw $[2,3]$. Crenshaw $[2,3]$ coined this term to emphasize the interplay of identities and social structures, particularly in how Black women were essentialized, treated and positioned differently in social structures due to race, gender, social class, White male patriarchy, and Western colonialism. Intersectionality lends itself exceptionally well to understanding the complexity of identities and people's experiences in relation to the historical, social, cultural, economic, and political context. In applying the intersectionality perspective to the lives of people with disabilities and their sexuality, the social work profession has the ability to commit itself to this endeavor. In an historical examination of social work's knowledge base, it demonstrates meaningful and inclusive scholarship and practice that has been developed for the purpose of social justice, equal access, full participation, and its reflection upon the multidimensionality of our clients and participants in research.

\section{References}

1. Council on Social Work Education.: Educational policy and accreditation standards. Retrieved from http://www.cswe.org/File.aspx?id=13780 (2008)

2. Crenshaw, K.: Demarginalizing the intersection of race and sex: a black feminist critique of antidiscrimination doctrine, feminist theory and antiracist politics. University of Chicago Legal Forum, 139-67 (1989)

3. Crenshaw, K.: Mapping the margins: intersectionality, identity politics, and violence against women of color. Stanf. Law Rev. 43, 1241-1299 (1991)

4. Jani, J.S., Ortiz, L., Pierce, D., Sowbel, L.: Access to intersectionality, content to competence: deconstructing social work education diversity standards. J. Soc. Work Educ. 47(2), 283-301 (2011)

5. LoGiudice, J., Linton, K., Algood, C., McAllister, C.: Disability and sexuality: what social worker educators should know. Council on Social Work Education, Annual Program Meeting: Dallas, TX (2013)

6. Mattsson, T.: Intersectionality as a useful tool: anti-oppressive social work and critical reflection. J. Women Soc. Work 29(1), 8-17 (2013)

7. National Association of Social Workers.: Code of ethics. Retrieved from http://www.socialworkers.org/ pubs/code/default.asp (2008) 